\title{
Identification of New Dibenzofurans from Distylium racemosum
}

\author{
Jeong Mi Kim, Ryeo Kỵeong Ko, Jin Won Hỵu,; and Nam Ho Lee* \\ Department of Chemistry, Cheju National Chiversity, Jeju 690-756. Korea. "E-mail: namhoiáchejuac.hr \\ tDepartment of Biochemistry, Graduate School of Hedicine, Cheju Kational Lniversity, Jeju 690-756, Korea \\ Received August 27, 2008, Accepted November 22, 2008
}

Key Wonds: Isolation. Structure identification. Dibenzofuran. Distritum racemosum

Disthim racenosum (Hamamelidaceae) is a large indecidious tree distributed over Halla Mountain in Jeju Island. Korea. We are continuously searching for the bioactive compounds applicable as functional cosmetic ingredients from plants in Jeju. ' From the ethanol extract of $D$. racemostm branches. we have found inhibition activities on elastase. Elastin degradation by elastase in denms is associated with aged skinwnnkle. - Since no chemucal investigation has been reported from the branches of this plant. we have conducted a phytochemical study to identify the active constituents. In this study. we have isolated new dibenzofuran compounds. 2,7-dlhỵdroxy-1.6-dimethoxy-9-methỵldibenzofuran (1) and 3.7-d1hydroxy -6-methosy-2,7-dimethy ldibenzofuran (2).

From the dried D. Recamosum collected in Jeju Island. ethanol extract was prepared. The extract was successively partitioned into hexane. ethyl acetate and $n$-butanol. The ethyl acetate fraction was further punfied by column chromatography over celite, silica gel and Sephadex LH-20 to afford the compounds 1 and 2 .

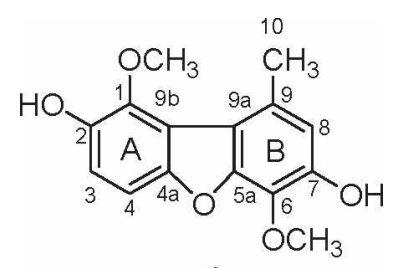

1
2

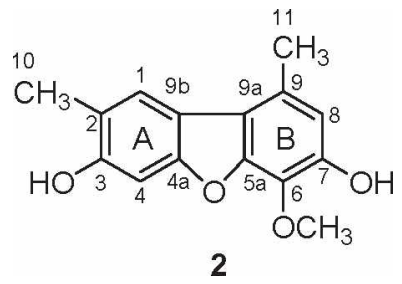

The compound 1 was white amorphous powder and its molecular formula was determuned as $\mathrm{C}_{1} \leqslant \mathrm{H}_{14} \mathrm{O}$; (nine unsaturation number) based on the lugh resolution $\mathrm{FAB}-\mathrm{MS}$ data. The UV spectrum of 1 showed absorption maxima at $290.4 \mathrm{~nm}$. indicating the presence of conjugated or aromatic system(s). The ${ }^{1} \mathrm{H}$ NMR spectrum of 1 in py ridine- $d_{5}$ (Table 1 ) showed signals for one methyl group at $\delta 2.98(3 \mathrm{H}, \mathrm{s})$, two methosy groups at $\delta+11(3 \mathrm{H} . \mathrm{s})$ and $+.12(3 \mathrm{H} . \mathrm{s})$. three aromatic protons at 7.41 (1H, d), 7.32 (1H.d). 7.17 (1H. s). The ${ }^{13} \mathrm{C}$ NMR data indicated the presence of $12 \mathrm{sp}^{2}$ carbons corresponding to two aromatic rings, and additionial one methyl and two $O-m e t h-$ yl carbons. Since two aromatic rings accounted for eight unsaturation number. compound 1 was inferred to have another ring, an ether linkage between aromatic nings to construct a dibenzofuran nucleus.

${ }^{l} \mathrm{H}$ NMR analysis indicated that two protons at o $7.32(\mathrm{H}-3)$ and $7.4 \mathrm{I}(\mathrm{H}-4)$ are located in ortho position by their doublet coupling constants $(J=8.8 \mathrm{~Hz})$. Since the proton at o 7.17 is singlet, its position should be located in another aromatic ning in dibenzofuran skeleton. The connectivities of the substituents in dibenzofuran 1 were determined by HMBC and NOESY experiments. HMBC correlations in $\mathrm{H}-3 / \mathrm{C}-1 . \mathrm{H}-3 / \mathrm{C}-4 \mathrm{a} . \mathrm{H}-4 /$ $\mathrm{C}-2 . \mathrm{H}-4 / \mathrm{C}-9 \mathrm{~b}$ showed the location of the carbons in ring $\mathrm{A}$ (Figure 1). The position of methoxy hydrogen $\left(1-\mathrm{OCH}_{3}\right)$ at $\delta$ 4.11 was assigned to be at $\mathrm{C}-\mathrm{I}$ by its ${ }^{3} j_{\mathrm{CH}} \mathrm{HMBC}$ cross peak.

In ring $B$. singlet at $\delta 7.17(\mathrm{H}-8)$ showed $\mathrm{HMBC}$ correlation with signals at $\hat{o} 132.2(\mathrm{C}-6)$ and $151.2(\mathrm{C}-7)$. Metlyyl (ồ2.98) and methoxy ( $(\hat{\delta} 4.12)$ were verified to be attached in ring $\mathrm{B}$ by their HMBC correlation with $\delta 116.2$ (C-8) and 129.4 (C-9), and $\delta 132.2(C-6)$, respectively. NOESY experiment showed the crosspeak between methyl protons $\left(\delta_{\mathrm{H}} 2.96\right)$ in ring $B$ and methoxy protons $\left(\vec{\partial}_{\mathrm{H}}+.12\right)$ in ring A. Since occurrence of NOESY correlation between substituents in different rings in 1 is possible at the positions of $\mathrm{C}-1$ and $\mathrm{C}-9_{,}{ }^{2}$ it is reasonable to assign the location of the methyl group at C-9 and the methosy group at $\mathrm{C}-1$. Methyl protons $(\mathrm{H}-10)$ also showed a NOESY correlation with a proton at $\hat{\delta}_{H} 7.17$. which supported the location of the proton signal $(\delta 7.17, \mathrm{H}-8)$. The position of the carbon signal at $\delta$ 132.2. showing HMBC correlation with methoxy protons. was assigned to $C-6$ rather than $C-7$ by the consideration of calculated $\delta_{c}$ values in benzene ning. ${ }^{4}$ Hyroxy protons at $\mathrm{C}-2$ and $\mathrm{C}-7$ were showed up in down field at ô 11.83 and 11.35 as singlets. From these spectroscopic data. the chemical structure of dibenzofuran 1 was completely determuned.

The occurrence of dibenzofuran denvatives from natural sources is relatively few. It is interesting to note that a dibenzofuran, kehokorin $B(3)$. has been recently isolated from my xomycete and it shared the same structure in ring A compared to $1 .{ }^{3}$ When we compared the ${ }^{13} \mathrm{C}$ NMR data for the carbons in A ring between compounds 1 and 3. it was found that their chemical shufts are well matching each other (Table 2).

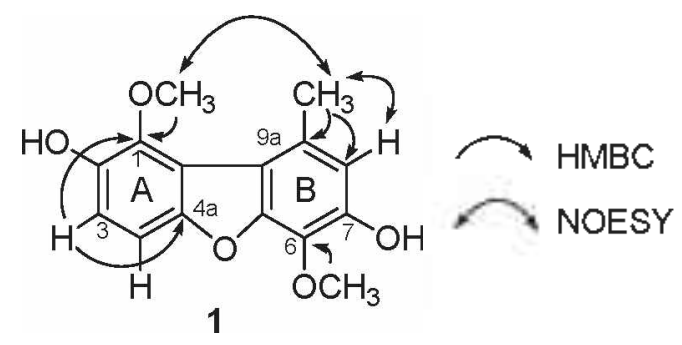

Figure 1. Key COSY and HMBC correlations in compound 1 
Table 1. 1D and 2D NMR data for 1 and 2 in $400 \mathrm{MHZ}$ ( for ${ }^{\mathrm{H}} \mathrm{H}$ ) NMR

\begin{tabular}{|c|c|c|c|c|c|c|}
\hline \multirow{2}{*}{$\begin{array}{c}\text { Compound } \\
\text { position }\end{array}$} & \multicolumn{3}{|c|}{1 (pyridine- $\left.t_{s}\right)$} & \multicolumn{3}{|c|}{$2\left(\mathrm{CD}_{3} \mathrm{OD}\right)$} \\
\hline & $\delta_{\mathrm{C}}$ & $\delta_{\mathrm{H}}($ int, mult, $J$ in $\mathrm{Hz})$ & $\operatorname{HMBC}(\mathrm{H} \rightarrow \mathrm{C})$ & $\delta_{c}$ & $\delta_{\mathrm{H}}(\mathrm{int}, \mathrm{mult}, J$ in $\mathrm{Hz})$ & $\mathrm{HMBC}(\mathrm{H} \rightarrow \mathrm{C})$ \\
\hline 1 & 142.8 & & & 123.4 & $7.58(\mathrm{IH}, \mathrm{s})$ & $\mathrm{C}-3, \mathrm{C}-4 \mathrm{a}, \mathrm{C}-10$ \\
\hline 2 & 147.9 & & & 121.6 & & \\
\hline 3 & 116.0 & $7.32(1 \mathrm{H}, \mathrm{d}, 8.8)$ & $C-1, C-4 a$ & 155.4 & & \\
\hline 4 & 107.5 & $7.41(1 \mathrm{H}, \mathrm{d}, 8.8)$ & $\mathrm{C}-2, \mathrm{C}-9 \mathrm{~b}$ & 98.5 & $6.94(1 \mathrm{H}, \mathrm{s})$ & $c-9 b$ \\
\hline $4 a$ & 131.6 & & & 157.3 & & \\
\hline $5 \mathrm{a}$ & 150.8 & & & 149.6 & & \\
\hline 6 & 132.2 & & & 132.2 & & \\
\hline 7 & 151.2 & & & 148.4 & & \\
\hline 8 & 116.2 & $7.17(1 \mathrm{H}, \mathrm{s})$ & $\mathrm{C}-6, \mathrm{C}-7$ & 1140 & $6.60(1 \mathrm{H}, \mathrm{s})$ & $C-6, C-9 a, C-11$ \\
\hline 9 & 129.4 & & & 127.6 & & \\
\hline $9 a$ & 117.2 & & & 118.4 & & \\
\hline $9 \mathrm{~b}$ & 120.2 & & & 118.3 & & \\
\hline 10 & 22.4 & $2.98(3 \mathrm{H}, \mathrm{s})$ & C $-8, C-9$ & 16.7 & $2.30(3 \mathrm{H}, \mathrm{s})$ & $\mathrm{C}-2, \mathrm{C}-3$ \\
\hline 11 & & & & 19.6 & $2.58(3 \mathrm{H}, \mathrm{s})$ & $C-8, C-9, C-9 a$ \\
\hline $\mathrm{I}-\mathrm{OCH}_{3}$ & 61.3 & $4.11(3 \mathrm{H}, \mathrm{s})$ & $\mathrm{C}-\mathrm{I}$ & & & \\
\hline $6-\mathrm{OCH}_{3}$ & 61.4 & $4.12(3 \mathrm{H}, \mathrm{s})$ & $\mathrm{C}-6$ & 61.5 & $4.03(3 \mathrm{H}, \mathrm{s})$ & $C-6$ \\
\hline$-\mathrm{OH}$ & & $11.35(1 \mathrm{H}, \mathrm{s})$ & & & & \\
\hline$-\mathrm{OH}$ & & $11.83(1 \mathrm{H}, \mathrm{s})$ & & & & \\
\hline
\end{tabular}<smiles>COc1ccc(-c2c(O)cc3c(oc4ccc(O)c(OC)c43)c2OC)cc1</smiles>

The molecular formula of 2 was revealed as $\mathrm{C}_{15} \mathrm{H}_{14} \mathrm{O}_{4}$ based on the high resolution FAB-MS and NMR data. The UV spectrum of $\mathbf{2}$ at $\lambda_{\text {max }} 296.4 \mathrm{~nm}$ indicated the presence of aromatic systems. The ${ }^{3} \mathrm{H}$ NMR spectrum of 2 in $\mathrm{CD}_{3} \mathrm{OD}$ (Table 1) showed signals for two metlyl groups at $\hat{o}_{\mathrm{H}} 2.58$ $(3 \mathrm{H} .5)$ and $2.30(3 \mathrm{H}, 5)$, one methoxy group at $\hat{o}_{\mathrm{H}}+.03(3 \mathrm{H}$. s). three aromatic lydrogens at $\hat{\delta}_{\mathrm{H}} 7.58(1 \mathrm{H}, \mathrm{s}) .6 .94(\mathrm{lH} . \mathrm{s})$. $6.60(1 \mathrm{H}, \mathrm{s})$. The ${ }^{13} \mathrm{C}$ NMR data indicated the presence of 12 $\mathrm{sp}^{2}$ carbons. and two methyl and one methoxy carbons. It was reasonable to assume that 2 has also dibenzofuran nucleus based on comparative analysis of ${ }^{1} \mathrm{H}$ and ${ }^{13} \mathrm{C}$ NMR data with those of 1 .

The position of the substituents were established by ID and

Table 2. Comparison of ${ }^{13} \mathrm{C} \mathrm{NMR}$ data for the carbons in ring $\mathrm{A}$ of 1 and 3

\begin{tabular}{ccc}
\hline position & 1 (pyridine- $d s$ ) & $\mathbf{3}$ (acetone- $d_{\text {c }}$ ) \\
\hline 1 & 142.8 & 142.8 \\
2 & 147.9 & 146.3 \\
3 & 116.0 & 117.6 \\
4 & 107.5 & 108.0 \\
$4 \mathrm{a}$ & 151.6 & 152.2 \\
$9 \mathrm{~b}$ & 120.2 & 119.3 \\
\hline
\end{tabular}

2D (HMBC and NOESY) NMR data. Three aromatic proton signals were all observed as singlets. which indicates that three protons are in separate spin system. The only possible orientation is that two protons are located in para positions in one ring and another proton is placed in the other ring. Closer examination of the NMR data indicated that $\mathbf{2}$ has the same chemical structure with 1 in ring $\mathrm{B}$. For example. carbon signals and HMBC correlation $(\mathrm{H}-8 / \mathrm{C}-6, \mathrm{H}-8 / \mathrm{C}-9 \mathrm{a} . \mathrm{H}-8 / \mathrm{C}-1 \mathrm{I})$ were almost identical between 1 and 2 in ring $B$. HMBC correlations of proton signals at $\hat{o} 7.58$ with $\delta 155.4 .157 .3,16.7$ as well as those of 0.94 with 0118.3 established the carbon connectivities in ring A. Since proton signal at ô 7.58 showed NOESY crosspeak with signal at $2.58(\mathrm{H}-\mathrm{ll})$, it is reasonable to assign a signal $\left(\delta_{\mathrm{H}} 7.58\right)$ to $\mathrm{H}-1$ based on stereochemical consideration. $\mathrm{H}-\mathrm{l}$ also showed another NOESY correlation with a signal at $\hat{\delta} 2.30$. which corroborated the attachment of the methyl group $(\mathrm{C}-10)$ to $\mathrm{C}-2$. From these spectroscopic data. the compound 2 was identified as 3.7-dihydrosy-6-methoxy-2.7-dimethyldibenzofuran.

The compounds 1 and 2 were examined for elastase inhibition activities. ${ }^{5}$ The compound 2 ( $\mathrm{IC}_{51}=7.7 \mu \mathrm{g} / \mathrm{ml}$ ) was more active than oleanolic acid ( $\mathrm{IC}_{s,}=9.7 \mu \mathrm{g} / \mathrm{ml}$ ). a compound commercially applied as the whitening ingredient in functional cosmetics. The compound 1 ( $\mathrm{IC}_{s,}=97.4 \mu \mathrm{g} / \mathrm{ml}$ ) showed slightly lower activity.

\section{Experimental Section}

Reagent and Equipment. Thin layer cluromatography was perfonmed on Merck prepared plates (silica gel $60 \mathrm{~F}-254$ on aluninumi). Colunu chromatography was performed using Merck silica gel 60 (230-400 mesh). Sephadex LH-20 
(25-100 $\mu \mathrm{m})$ for Gel filtration chromatography (GFC) was obtained from Fluka. The UV absorbance was perfonmed with a Biochrom Libra \$22 UV-visible spectrophotometer. ${ }^{1} \mathrm{H}$ $(400 \mathrm{MHz})$ and ${ }^{13} \mathrm{C}(100 \mathrm{MHz}) \mathrm{NMR}$ spectra were recorded on a JNM-LA 400 (JEOL) instrument. with chemical shift data reported in ppm relative to the solvent used. 2D NMR spectra were recorded on the same instrument using field gradient FG2 (inverse) probe. Melting point was recorded on Fisher Scientific 12-132T. High resolution MS data was obtained from the Korea Basic Science Institute in Seoul.

Isolation of the Compounds 1 and 2 . The branches of $D$. racemostm were collected from Halla Botanical Garden in Jeju Island. and air-dried and cut into small pieces. The voucher specimen (J-242) was prepared and deposited in the laboratory of natural product. department of chemistry. Cheju National University.

The dried D. racemostm powder $(2.5 \mathrm{~kg})$ was suspended in $25 \mathrm{~L}$ of $70 \% \mathrm{EtOH}$ and mechanically stirred for $24 \mathrm{~h}$ at room temperature. The solution was filtered and the residue was extracted one more time. The filtrates were combined and concentrated under reduced pressure to give the oily extract (270 g). After the extract was suspended in $2 \mathrm{~L}$ of distilled water. successive solvent fractionation was performed using $n$-hexane ethyl acetate and $n$-butanol. The EtOAc fraction (45 g) was chromatographed over celite with $n$-hexane, $\mathrm{CH}_{2} \mathrm{Cl}_{2}$. $\mathrm{CHCl}_{3}, \mathrm{Et}_{2} \mathrm{O}$. EtOAc and $\mathrm{MeOH}$ successively. The obtained diethyl ether subfraction was chromatographed over reversedphase silica gel with gradient solvent $\left(\mathrm{H}_{2} \mathrm{O}-\mathrm{MeOH}\right)$ system to provide 12 fractions (Fr-1 to Fr-12). The ninth fraction (Fr-9) was further purified by silica gel column chromatography (CC) with $\mathrm{CHCl}_{3} / \mathrm{MeOH}(+/ 1)$ and the obtained subfraction was recrystallized to give the compound $1(63.9 \mathrm{mg})$. The compound 2 ( $4.9 \mathrm{mg}$ ) was obtained from Fr-10 by Sephadex $\mathrm{LH}-20 \mathrm{CC}$ with $\mathrm{CHCl}_{3} / \mathrm{MeOH}(8 / 1)$.

2,7-Dihydoxy-1,6-dimethoxy-9-methyldibenzofuran (1) White amorphous powder, UV $\left(\mathrm{CH}_{3} \mathrm{OH}\right) 290.4$; Melting point $178-182^{\circ} \mathrm{C}$ : HR-FABMS data $\left[m / z 274.0832(\mathrm{M})^{-}\right.$. calcd for $\mathrm{C}_{1 \leqslant \mathrm{H}_{1}} \mathrm{O} ; 274.08+1, \triangle-0.9 \mathrm{munul}$. For ${ }^{1} \mathrm{H}$ and ${ }^{13} \mathrm{C}$ NMR data. see Table 1: NOESY correlations $(\mathrm{H} \leftrightarrow \mathrm{H} \#)$ $6-\mathrm{OCH}_{3} \leftrightarrow \mathrm{H}_{2}-10 . \mathrm{H}_{2}-10 \leftrightarrow \mathrm{H}-8$

3,7-Dihydlroxy-6-methoxy-2,7-dimethyldibenzofuran (2) White amorphous powder: UV $\left(\mathrm{CH}_{3} \mathrm{OH}\right) 296$ : $\mathrm{HR}-\mathrm{FABMS}$ data $\left[m / z 258.0894(\mathrm{M})^{-}\right.$, calcd for $\mathrm{C}_{15} \mathrm{H}_{14} \mathrm{O}_{4} 258.0892$. $\triangle$ $-0.2 \mathrm{mmu}$. For ${ }^{1} \mathrm{H}$ and ${ }^{13} \mathrm{C}$ NMR data. see Table 1: NOESY correlations $(\mathrm{H} \leftrightarrow \mathrm{H} \#) \mathrm{H}-1 \leftrightarrow \mathrm{H}_{5}-10, \mathrm{H}-1 \leftrightarrow \mathrm{H}_{5}-11$

Acknowledgments. This research was performed under the program of Basic Atomic Energy Research Institute (BAERI) which is a part of the Nuclear R\&D Programs funded by the Ministry of Science \& Technology (MOST) of Korea.

\section{References}

1. (a) Sultana, N.: Lee, N. H. Phutotherapv Res. 2007, 21, 1171. (b) Ham, Y. M. Hyun, J. W. Lee, N. H. Bull. Korean Chem. Soc. 2007, 28, $1595^{\circ}$ (c) Kim, Y. H.; Kim, K. S.: Han, C. S.: Yang, H. C.: Park, S. H.: Ko, K. I.; Lee, S. H.; Kim, K. H.; Lee, N. H.; Kim. T. M.; Son. K.-H. J. Cosmet Sci. 2007, 58 , 19. (d) Ko, R. K.; Lee, N. H. Bull Korean Chem. Soc. 2008, 29, 2531.

2. Bammann, L. Cosmetic Dematolog, Principles and Practice, McGraw-Hill: New York, U.S.A., 2002; p 10.

3. Kanisa, K: Ohtsuki, 1 : Yamamoto, $Y$; Ishibashi, M. Tetrahedron Lett. 2006, $\$ 7,1505$

4. Crews, P.; Rodrigues, T. Taspars, M. Ungonic Sinzture Analusis: Oxtord: New York U.S.A. 1998; p 90

5. James, A. E. K.: I imothy, L. W.: Gordon, L. Biochemismy 1996, 35,9090 